\title{
Knowledge, attitudes and beliefs about chronic noncancer pain in primary care: A Canadian survey of physicians and pharmacists
}

\author{
Lyne Lalonde $\mathrm{PhD}^{1,2,3,4}$, Vincent Leroux-Lapointe $\mathrm{BSC}^{4,5}$, Manon Choinière $\mathrm{PhD}^{3,6}$, Elisabeth Martin $\mathrm{MSc}^{3,4}$, \\ David Lussier $\mathrm{MD}^{7,8}$, Djamal Berbiche $\mathrm{PhD}^{3,4}$, Diane Lamarre $\mathrm{MSc}^{1,9}$, Robert Thiffault $\mathrm{MSc}^{10}$, \\ Ghaya Jouini $\mathrm{MSc}^{3,4}$, Sylvie Perreault $\mathrm{PhD}^{1,11}$
}

L Lalonde, V Leroux-Lapointe, M Choinière, et al. Knowledge, attitudes and beliefs about chronic noncancer pain in primary care: A Canadian survey of physicians and pharmacists. Pain Res Manag 2014;19(5):241-250.

BACKGROUND: Primary care providers' knowledge, attitudes and beliefs $(\mathrm{KAB})$ regarding chronic noncancer pain $(\mathrm{CNCP})$ are a barrier to optimal management.

OBJECTIVES: To evaluate and identify the determinants of the KAB of primary care physicians and pharmacists, and to document clinician preferences regarding the content and format of a continuing education program (CEP).

METHOD: Physicians and pharmacists of 486 CNCP patients participated. Physicians completed the original version of the KnowPain-50 questionnaire. Pharmacists completed a modified version. A multivariate linear regression model was developed to identify the determinants of their KAB.

RESULTS: A total of 137 of 387 (35.4\%) physicians and 110 of $278(39.5 \%)$ pharmacists completed the survey. Compared with the physicians, the pharmacists surveyed included more women (64\% versus $38 \%$ ) and had less clinical experience (15 years versus 26 years). The mean KnowPain-50 score was $69.3 \%$ (95\% CI $68.0 \%$ to $70.5 \%$ ) for physicians and $63.8 \%$ (95\% CI $62.5 \%$ to $65.1 \%$ ) for pharmacists. Low scores were observed on all aspects of pain management: initial assessment (physicians, $68.3 \%$; pharmacists, $65.4 \%$ ); definition of treatment goals and expectations $(76.1 \%$; 61.6\%); development of a treatment plan $(66.4 \% ; 59.0 \%)$; and reassessment and management of longitudinal care $(64.3 \% ; 53.1 \%)$. Ten hours of reported CEP sessions increased the KAB score by 0.3 points. All clinicians considered a CEP for CNCP to be essential. Physicians preferred an interactive format, while pharmacists had no clear preferences. CONCLUSION: A CEP to improve primary care providers' knowledge and competency in managing $\mathrm{CNCP}$, and to reduce false beliefs and inappropriate attitudes regarding $\mathrm{CNCP}$ is relevant and perceived as necessary by clinicians.

Key Words: Beliefs; Chronic noncancer pain; Knowledge; Physicians and pharmacists; Primary care

$\mathrm{C}$ hronic noncancer pain $(\mathrm{CNCP})$ is defined as pain that persists for $>6$ months (1). In Canada, as in other industrialized countries, approximately $20 \%$ of the population experiences CNCP $(2-5)$. Its prevalence is constantly increasing as the population ages $(2,3,6)$. $\mathrm{CNCP}$ is associated with major psychosocial distress for affected
Les connaissances, les attitudes et les croyances sur les douleurs chroniques non cancéreuses en première ligne : un sondage canadien auprès des médecins et des pharmaciens

HISTORIQUES : Les connaissances, les attitudes et les croyances (CAC) des dispensateurs de soins de première ligne envers les douleurs chroniques non cancéreuses (DCNC) font obstacle à une prise en charge optimale. OBJECTIFS : Évaluer et établir les déterminants des CAC des médecins et pharmaciens de première ligne et étayer les préférences cliniques relatives au contenu et à la structure d'un programme de perfectionnement professionnel continu (PPC).

MÉTHODOLOGIE : Les médecins et les pharmaciens de 486 patients ayant des DCNC ont participé à l'étude. Les médecins ont rempli la version originale du questionnaire KnowPain-50, tandis que les pharmaciens en ont utilisé une version modifiée. Les chercheurs ont préparé un modèle de régression linéaire multivariée pour établir les déterminants de leurs CAC. RÉSULTATS : Au total, 137 des 387 médecins (35,4\%) et 110 des 278 pharmaciens $(39,5 \%)$ ont rempli le sondage. Par rapport aux médecins, les pharmaciens sondés comprenaient davantage de femmes (64\% comparativement à $38 \%$ ) et avaient moins d'expérience clinique (15 ans comparativement à 26 ans). L'indice moyen du questionnaire KnowPain-50 s'établissait à $69,3 \%$ (95\% IC 68,0 \% à 70,5\%) pour les médecins et à $63,8 \%$ (95 \% IC 62,5 \% à 65,1\%) pour les pharmaciens. Tous les aspects de la gestion de la douleur ont donné des indices faibles : évaluation initiale (médecins, 68,3\%; pharmaciens, 65,4\%), définition des objectifs et attentes thérapeutiques $(76,1 \% ; 61,6 \%)$, élaboration d'un plan thérapeutique $(66,4 \% ; 59,0 \%)$ et réévaluation et prise en charge des soins longitudinaux (64,3\%; 53,1 \%). Des séances de PPC d'une durée de dix heures amélioraient l'indice de CAC de 0,3 point. Tous les cliniciens jugeaient essentielle la tenue d'un PPC sur les DCNC. Les médecins préféraient une structure interactive, tandis que les pharmaciens n'avaient pas de préférences claires. CONCLUSION : Il est pertinent de préparer un PPC pour améliorer les connaissances et les compétences des dispensateurs de soins de première ligne envers les DCNC et pour réduire les croyances erronées et les attitudes inadéquates au sujet des DCNC, et les cliniciens le perçoivent comme nécessaire.

individuals and their relatives, and with a heavy economic burden for society as a whole (6-9).

Current management of CNCP is often associated with suboptimal clinical outcomes in terms of pain relief and health-related quality of life $(7,10)$, particularly in primary care, where most of these patients

${ }^{1}$ Faculty of Pharmacy, Université de Montréal, Montreal; '2Sanofi Aventis Endowment Chair in Ambulatory Pharmaceutical Care, Université de

Montréal and Centre de santé et de services sociaux de Laval; ${ }^{3}$ Centre de recherche du Centre hospitalier de l'Université de Montréal, Montreal;

${ }^{4}$ Équipe de recherche en soins de première ligne, Centre de santé et de services sociaux de Laval, Laval; ${ }^{5}$ Department of Medicine; ${ }^{6}$ Department

of Anesthesiology, Faculty of Medicine; ${ }^{7}$ Institut universitaire de gériatrie de Montréal, Department of Medicine, Université de Montréal;

${ }^{8}$ Division of Geriatric Medicine, McGill University Health Centre, Department of Medicine, McGill University; ${ }^{9}$ Ordre des pharmaciens du

Québec, Montreal; ${ }^{10}$ Centre hospitalier universitaire de Sherbrooke, Sherbrooke; ${ }^{11}$ Sanofi Aventis Endowment Chair in Drug Utilization,

Faculty of Pharmacy, Université de Montréal, Montreal, Quebec

Correspondence: Dr Lyne Lalonde, Centre de recherche du Centre hospitalier de l'Université de Montréal, 850 St-Denis Street, room S03.436, Montreal, Quebec H2X 0A9. Telephone 514-890-8000 ext 15491, fax 514-412-7038, e-mail lyne.lalonde@umontreal.ca 
are followed (5,10-15). In the United States, it has been estimated that $>40 \%$ of patients with chronic pain experience uncontrolled pain (16). In a Canadian survey (7), a large proportion of patients taking prescribed analgesics reported high levels of pain interference with day-to-day activities (37\% of all patients with pain and $59 \%$ of those reporting severe pain). In this population, the prevalence of depression and anxiety $(4,6)$ as well as sleep problems (5) is high. In fact, primary care clinicians themselves believe that more than one-half of their patients are not receiving optimal treatment $(15,17)$. Moreover, the therapeutic gaps between recommended and actual pain treatment may be contributing to increase the incidence of chronic pain (7).

Several studies have suggested that suboptimal clinical care may be due, in part, to deficient knowledge, false beliefs and inappropriate attitudes among clinicians regarding pain and its treatment (10-15). The main barriers to optimal treatment reported by clinicians were side effects (cited by $74 \%$ of respondents), patient compliance $(58 \%)$, and concerns about the efficacy of available therapies (60\%) (15). With respect to opioid treatment, the barriers to optimal pain management most frequently mentioned by primary care physicians were fear of opioid dependency and of significant side effects, and the potential for misuse and abuse $(7,13,17-19)$. These considerations may explain why $52 \%$ of physicians said they systematically have their patients evaluated by a specialist before prescribing opioids (20). Pharmacists are also reluctant to dispense opioids; $58.3 \%$ believe that $\mathrm{CNCP}$ patients are liable to develop addiction (14). A continuing education program (CEP) may be an important factor in improving treatment outcomes. However, to develop programs that target the needs and preferences of clinicians, a better understanding of their knowledge, attitudes and beliefs (KAB) about pain and its treatment is essential.

As part of the ACCORD Program (Application Concertée des Connaissances et Ressources en Douleur), a knowledge-translation research program on $\mathrm{CNCP}$, a cohort study was conducted to describe the management of $\mathrm{CNCP}$ patients in primary care (21). A total of 486 patients with moderate to severe $\mathrm{CNCP}$ were recruited in community pharmacies located in urban and semiurban areas $(22,23)$. Considerable proportions of the patients had probable depression $(23.9 \%)$ and anxiety $(39.9 \%)$. The prevalence of analgesic side effects was as high as $95.5 \%$, and these were often left untreated. Patient satisfaction with treatment was low, particularly with regard to information about pain and its treatment. For patients, the greatest barriers to optimal management included fatalistic beliefs and fear of the harmful effects of pain medicine in general.

The current report presents the results of a cross-sectional survey of primary care physicians and pharmacists involved in following the ACCORD cohort patients. It was conducted to evaluate their KAB about pain and its treatment, identify the determinants of better KAB and document their preferences regarding the content and format of a CEP.

\section{METHODS}

The ACCORD Program is funded by the Canadian Institutes of Health Research through the Community Alliances for Health Research and Knowledge Exchange on Pain. It comprises five axes of research: geoepidemiology, primary care, nursing home, patient selfmanagement and pain awareness/education program (21). Within the primary care axis, a cohort of $486 \mathrm{CNCP}$ patients was formed. The primary care physicians and pharmacists of these patients were asked to complete a self-administered questionnaire to assess $\mathrm{KAB}$ regarding pain and its treatment. Ethical approval was obtained from the Scientific and Ethics Research Committee of the Centre de santé et de services sociaux de Laval, Laval, Quebec. All participants signed a consent form and received financial compensation (\$25).

\section{Participants}

Consultation of the provincial health ministry atlas (24) yielded a total of 513 pharmacies in the territory of the Integrated University Health Network of the Université de Montréal in six health and social services regions: Mauricie and Centre du Québec, Laval, Montréal, Laurentides, Lanaudière and Montérégie. Based on this sampling frame, a random sampling, stratified according to region and weighted according to the number of pharmacies within each region, was performed to recruit a total of 60 pharmacies. The owners were contacted and invited to participate. Pharmacies in each region were approached until the target was reached. To recruit 600 patients, every participating pharmacy was asked to identify between 10 and 15 consecutive, potentially eligible patients. The criteria for patient eligibility were: age $\geq 18$ years; experiencing CNCP, defined as pain lasting for $\geq 6$ months and not related to cancer; reporting an average pain intensity in the past seven days of at least 4 on a 0 to 10 scale, where 0 represents 'no pain' and 10 represents 'the worst possible pain'; experiencing pain at least two days per week; having an active analgesic prescription from a primary care physician; and able to speak and read French or English. Patients who had migraine as the sole cause of pain were excluded, as were those with any health problem that might prevent them from providing informed consent. To compensate for pharmacies that did not recruit the expected number of patients, additional pharmacies were invited to participate during the course of the study.

From May to October 2009, 296 community pharmacies were randomly selected and invited to participate; of these, 84 (28.4\%) were recruited, representing 278 pharmacists. At the time of recruitment, all participating pharmacists were asked to complete the survey, and the questionnaire was sent to those who agreed. To increase the response rate, they received a telephone call every two weeks for two months or until the questionnaire was returned. Participating pharmacists recruited a total of $486 \mathrm{CNCP}$ cohort patients.

Using their pharmacy dispensing chart for each cohort patient, pharmacists identified a primary care physician prescriber of an active analgesic prescription including acetaminophen, nonsteroidal antiinflammatory drugs (NSAIDs), anticonvulsants, antidepressants, muscle relaxants and opioids. Each of these physicians was asked to complete a self-administered questionnaire. A modified version of Dillman's Tailored Design Method (25) was used from January to March 2010. The physicians first received a personalized letter of invitation describing the study. One week later, they received a selfadministered questionnaire, an informed consent form and a postage-paid return envelope. Two weeks later, they received a postcard to remind them to complete and return the questionnaire. Three weeks later, nonrespondents were sent the questionnaire again. Two weeks after that, nonrespondents were mailed the questionnaire a third time.

\section{Survey}

The questionnaire was written in French. It comprised 15 pages for pharmacists and 16 pages for physicians, including a cover page and an instruction page. It was divided into three sections addressing KAB regarding pain and its treatment, sociodemographic information and previous training, and needs and preferences for a CEP.

The KnowPain-50 questionnaire was developed by pain physicians to measure the $\mathrm{KAB}$ of physicians regarding chronic pain and its treatment (12). It comprises 50 items divided into six subscales: initial pain assessment (13 items); defining goals and expectations (10 items); development of a treatment plan (16 items); implementation of a treatment plan (three items); reassessment and management of longitudinal care (one item); and management of environmental issues (seven items). The questionnaire includes 45 Likert-scale questions and five multiple-choice questions. For each Likert-scale question, respondents can be awarded a score ranging from 0 (incorrect answer/strongly agree) to 5 (correct answer/ strongly disagree) depending on their level of agreement with each statement. The response scales for 20 items (questions 6, 8, 16-18, 21, 23, 26-34, 37, 43, 44 and 46) are inverted (scores of 5, 4, 3, 2, 1 and 0 transformed into a score of $0,1,2,3,4$ and 5 , respectively). For multiple-choice questions, correct answers receive five points. Overall and subscale scores are expressed as the sum of the individual scores (absolute score) and as a percentage score (absolute score/maximum possible score $\times 100 \%$ ). The range for total overall absolute scores is 0 to 250 (a higher score indicating better knowledge). In one study (12), the Cronbach alpha reliability index was high in three different populations of physicians (0.77 to 0.85 ); 


\begin{tabular}{|c|c|c|c|c|}
\hline & \multicolumn{2}{|c|}{ Pharmacists $(n=110)$} & \multicolumn{2}{|c|}{ Physicians (n=137) } \\
\hline & Items, n & Cronbach alpha $(95 \% \mathrm{Cl})$ & Items, $\mathbf{n}$ & Cronbach alpha $(95 \% \mathrm{Cl})$ \\
\hline \multicolumn{5}{|l|}{ Subscale } \\
\hline Initial pain assessment & 8 & $0.50(0.34$ to 0.63$)$ & 13 & 0.53 (0.40 to 0.64$)$ \\
\hline Development of a treatment plan & 15 & 0.55 (0.41 to 0.67$)$ & 16 & 0.64 (0.54 to 0.73$)$ \\
\hline Implementation of a treatment plan & 3 & $0.25(-0.03$ to 0.46$)$ & 3 & $0.22(-0.04$ to 0.42$)$ \\
\hline Reassessment and management of longitudinal care & 1 & - & 1 & - \\
\hline Pharmacotherapy & 7 & $-0.03(-0.37$ to 0.25$)$ & 7 & $0.03(-0.25$ to 0.27$)$ \\
\hline Original overall scale & 43 & $0.66(0.55$ to 0.75$)$ & 50 & 0.77 (0.71 to 0.83$)$ \\
\hline Modified overall scale* & 50 & 0.64 (0.53 to 0.74$)$ & 50 & 0.77 (0.71 to 0.83 ) \\
\hline
\end{tabular}

*The modified overall scale includes 43 questions from the original scale plus seven questions developed by a panel of experts to specifically assess the knowledge, attitudes and beliefs of pharmacists. Refer to the methods section for more information

the overall score correlated with clinical behaviour and appeared to distinguish between physicians who had participated in different pain management education programs. In another study (26), Knowpain-50 was responsive to education interventions. The original English version was translated into French using a forward-backward translation process (27). The French version is available on request.

A panel of experts, including three pharmacists, one primary care physician with expertise in chronic pain management and one geriatrician, assessed the relevance of the KnowPain-50 questionnaire for evaluating the $\mathrm{KAB}$ of pharmacists. By consensus of the panel, seven items were considered to be inappropriate in the following subscales: initial pain assessment (questions 1, 15, 17, 18 and 38); defining goals and expectations (question 23); and development of a treatment plan (question 43). One panel member (a hospital pharmacist with expertise in chronic pain management) proposed an initial set of 10 multiplechoice questions on the pharmacotherapy of CNCP. By consensus of all members of the panel, seven of these questions were selected and modified when deemed appropriate: recommendations regarding initial treatment of CNCP; management of constipation in patients taking opioids; recommendation regarding use of NSAIDs; recommendation regarding use of acetaminophen versus NSAIDs; opioid dosage conversion; treatment of fibromyalgia; and adverse effects of tricyclic antidepressants in elderly patients. Each correct answer would receive a score of 5. Physicians completed the original 50-item questionnaire along with these seven additional items (total of 57 items). Pharmacists completed only the modified questionnaire including the 43 original items and the seven additional items (total of 50 items).

Three questions were used to evaluate the clinicians' perceived learning needs and their preferences regarding the format and content for a CEP. Clinicians were asked: "From your standpoint, is there a need for a CEP in CNCP for primary care physicians (or pharmacists)?" (Yes/No). Preferences regarding the optimal format for such a program were elicited by asking respondents: "What would be the best educational vehicle(s) or method(s) for a CEP?" Participants could check off one or more of the listed items and add their own suggestions as well. To elicit their recommendations regarding the content of the program, they were asked: "In which area(s) would you like to have more training with regard to CNCP?" Once again, they could check off one or more listed items and add their own suggestions. Items were predefined by our panel of experts. They identified topics of interest for both physicians and pharmacists (treatment guidelines and pharmacotherapy) as well as topics specifically for physicians (eg, assessment, follow-up, diagnosis, methods of treatment) and others for pharmacists (eg, detection and management of drug-related problems and side effects, and collaborative practices with physicians).

\section{Statistical analyses}

The response rate was assessed for physicians and pharmacists. Their characteristics were described using proportions and means \pm SD. For physicians, the overall original KnowPain-50 score (including the original 50 items) and the modified score (including the original 43 items plus the seven new items) were computed. For pharmacists, the overall original score (including the original 43 items) and the overall modified score (including the original 43 items plus the seven new items) were computed. Subscale and overall scores were calculated when at least $90 \%$ of the questions were answered. Missing data were replaced by the respondent's mean score calculated using the available results. A sensitivity analysis was performed by replacing missing responses by a score of zero. The mean \pm SD absolute overall and subscale scores and their $95 \%$ CIs were computed for pharmacists and physicians. The Cronbach alpha reliability coefficients $(95 \% \mathrm{CI})$ for the original and modified versions were computed for each subscale and the overall scale.

A multivariate linear regression model was developed to identify the determinants of higher overall absolute KnowPain-50 scores based on the original scale for physicians ( 50 questions) and the modified scale for pharmacists (50 questions). The independent variables in the models included type of clinician (physician/pharmacist), sex, years since graduation and hours of reported CEP sessions in chronic pain in the past five years. A type 1 error of 0.05 was used as the threshold of statistical significance.

Univariate logistic models were used to assess the likelihood of clinicians' identifying a need for more training in a specific area (dependent variable) as a function of scores on the KnowPain-50 subscales and the new pharmacotherapy subscale (independent variables). Statistical analyses were performed using SPSS version 19.0 (IBM Corporation, USA) for Windows (Microsoft Corporation, USA), and SAS version 9.1 (SAS Inc, USA).

\section{RESULTS}

A total of 278 community pharmacists were recruited in the ACCORD cohort study and asked to complete the survey; 129 agreed and $110(39.6 \%)$ returned their completed questionnaire. The pharmacists identified a total of 486 eligible CNCP patients, who were followed by 387 primary care physicians. These physicians were asked to complete the survey; 137 (35.4\%) returned their completed questionnaire. For two respondents, the overall KnowPain-50 score could not be calculated because they left $>10 \%$ of the questions unanswered.

As reported in Table 1, the Cronbach alpha reliability coefficients for the original and modified versions of the KnowPain-50 questionnaire were similar for both pharmacists (original [based on 43 items]: 0.66; modified [50 items]: 0.64) and physicians (original [50 items]: 0.77 ; modified [50 items]: 0.77). The coefficients were lower for pharmacists (eg, 0.66 for pharmacists versus 0.77 for physicians on the original overall scale); however, given the overlapping of the $95 \%$ CI (pharmacists, 0.55 to 0.75 ; physicians, 0.71 to 0.83 ), the differences were not statistically significant. The subscale coefficients varied from -0.03 to 0.55 for pharmacists and from 0.03 to 0.64 for physicians; they were particularly low for the 'Pharmacotherapy' subscale. 
TABLE 2

Characteristics of the primary care physicians, pharmacists and pharmacies who participated in the present study

\begin{tabular}{|c|c|c|}
\hline Characteristics of clinicians & Pharmacists $(n=110)^{*}$ & Physicians $(n=137)^{*}$ \\
\hline \multicolumn{3}{|l|}{ Sex } \\
\hline Male/female & $40(36.4) / 70(63.6)$ & $84(61.8) / 52(38.2)$ \\
\hline \multicolumn{3}{|l|}{ Year of graduation } \\
\hline $1991-2000$ & $36(32.7)$ & $17(12.4)$ \\
\hline$\leq 1990$ & $38(34.5)$ & $114(83.2)$ \\
\hline Yes & $23(20.9)$ & $34(24.8)$ \\
\hline Bachelors & $13(11.8)$ & $28(20.4)$ \\
\hline Masters & $10(9.1)$ & $6(4.4)$ \\
\hline Exposure to continuing education program on chronic pain in past five years & $47(42.7)$ & $115(83.9)$ \\
\hline If yes, time spent in continuing education on chronic pain in past five years, $h$, mean $\pm S D$ & $23.1 \pm 41.6$ & $44.6 \pm 84.7$ \\
\hline \multicolumn{3}{|l|}{ Type of pharmacist } \\
\hline Chain and banner/independent & $60(96.8) / 2(3.2)$ & \\
\hline \multicolumn{3}{|l|}{ Surface area, square feet } \\
\hline$<1000$ & $9(15.0)$ & \\
\hline $1000-2499$ & $11(18.3)$ & \\
\hline $2500-4999$ & $12(20.0)$ & \\
\hline$\geq 5000$ & $28(46.7)$ & \\
\hline Opening hours per week, $h$, mean $\pm S D$ & $75.4 \pm 14$ & \\
\hline Opening hours per week, pharmacist hours, mean \pm SD & $88.3 \pm 27$ & \\
\hline \multicolumn{3}{|l|}{ Area available for private consultations } \\
\hline Yes/no & $61(98.4) / 1(1.6)$ & \\
\hline
\end{tabular}

Data presented as $n(\%)$ unless otherwise indicated. ${ }^{*}$ Missing data if total number of respondents is lower than the total number of participants.

TABLE 3

Knowledge, attitudes and beliefs of primary care physicians and pharmacists regarding chronic noncancer pain and its treatment as evaluated with the KnowPain-50 questionnaire

\begin{tabular}{|c|c|c|c|c|c|c|c|c|}
\hline & \multicolumn{4}{|c|}{ Pharmacists $(n=110)$} & \multicolumn{4}{|c|}{ Physicians ( $n=137)$} \\
\hline & \multirow[b]{2}{*}{ Items, $\mathbf{n}$} & \multirow{2}{*}{$\begin{array}{c}\text { Absolute } \\
\text { score, } \\
\text { mean } \pm \text { SD }\end{array}$} & \multicolumn{2}{|c|}{ Percentage point score } & \multirow[b]{2}{*}{ Items, $\mathbf{n}$} & \multirow{2}{*}{$\begin{array}{c}\text { Absolute } \\
\text { score, } \\
\text { mean } \pm \text { SD }\end{array}$} & \multicolumn{2}{|c|}{ Percentage point score } \\
\hline & & & Mean \pm SD & $95 \% \mathrm{Cl}$ & & & Mean \pm SD & $95 \% \mathrm{Cl}$ \\
\hline \multicolumn{9}{|l|}{ Subscale scores } \\
\hline Initial pain assessment & 8 & $26.2 \pm 4.2$ & $65.4 \pm 10.6$ & $63.4-67.5$ & 13 & $44.4 \pm 5.9$ & $68.3 \pm 9.0$ & $66.7-69.8$ \\
\hline Defining goals and expectations & 9 & $27.7 \pm 4.3$ & $61.6 \pm 9.5$ & $59.8-63.4$ & 10 & $38.0 \pm 4.4$ & $76.1 \pm 8.8$ & $74.6-77.6$ \\
\hline Development of a treatment plan & 15 & $44.2 \pm 7.8$ & $59.0 \pm 10.4$ & $57.0-61.0$ & 16 & $53.1 \pm 8.4$ & $66.4 \pm 10.5$ & $64.6-68.2$ \\
\hline Implementation of a treatment plan & 3 & $11.0 \pm 3.0$ & $73.1 \pm 20.1$ & $69.3-77.0$ & 3 & $11.7 \pm 2.1$ & $78.0 \pm 14.0$ & $75.7-80.4$ \\
\hline $\begin{array}{l}\text { Reassessment and management of } \\
\text { longitudinal care }\end{array}$ & 1 & $2.7 \pm 1.3$ & $53.1 \pm 26.9$ & $48.0-58.2$ & 1 & $3.2 \pm 1.2$ & $64.3 \pm 23.8$ & $60.2-68.3$ \\
\hline Management of environmental issues & 7 & $22.6 \pm 4.1$ & $64.4 \pm 11.8$ & $62.2-66.7$ & 7 & $22.6 \pm 4.9$ & $64.8 \pm 14.0$ & $62.3-67.1$ \\
\hline Pharmacotherapy & 7 & $25.6 \pm 6.1$ & $73.0 \pm 17.3$ & $69.6-76.5$ & 7 & $25.2 \pm 6.9$ & $71.9 \pm 19.6$ & $68.4-75.3$ \\
\hline Original overall score & 43 & $134.3 \pm 14.5$ & $62.5 \pm 6.8$ & $61.2-63.8$ & 50 & $172.1 \pm 18.6$ & $69.4 \pm 7.6$ & $68.2-70.7$ \\
\hline Modified overall score & 50 & $159.5 \pm 17.4$ & $63.8 \pm 7.0$ & $62.5-65.1$ & 50 & $173.2 \pm 18.3$ & $69.3 \pm 7.3$ & $68.0-70.5$ \\
\hline
\end{tabular}

Table 2 shows that the pharmacists were mainly women (63.6\%), having graduated a mean of 15 years previously. Forty-three percent of pharmacists had attended a CEP on chronic pain in the previous five years. Because all the surveyed pharmacists were participants in the ACCORD cohort study, it was possible to compare pharmacists who completed the survey with those who did not in terms of sex, type (owner or salaried) and pharmacy characteristics (type, size, number of business hours, availability of a private consultation area); no significant differences were found. Physicians were mainly men (61.8\%) and had a mean of 26 years' experience since graduation. Most (83.9\%) had attended a CEP about chronic pain in the previous five years. No data were available regarding physicians who did not complete the survey.

As reported in Table 3, the original overall unadjusted mean scores on the KnowPain-50 questionnaire were $62.5 \%$ (95\% CI $61.2 \%$ to $63.8 \%$ ) for pharmacists and $69.4 \%$ (95\% CI $68.2 \%$ to $70.7 \%$ ) for physicians. Similar results were obtained with the modified version of the questionnaire (pharmacists, 63.8\% [95\% CI 62.5\% to 65.1\%]; physicians, $69.3 \%$ [95\% CI 68.0\% to 70.5\%]). Replacing missing responses by a score of zero did not substantially change the results. The highest mean subscale scores for both pharmacists and physicians were on 'Implementation of a treatment plan' (pharmacists, 73.1\%; physicians, 
78.0\%) and 'Pharmacotherapy' (pharmacists, 73.0\%; physicians, $71.9 \%$ ). These scales involve general notions of the pharmacotherapy of chronic pain and the management of analgesic side effects. Scores were lower on the subscales dealing with specific patient populations (eg, the elderly or those at risk of addiction) and a specific type of pain (eg, neuropathic pain): 'Initial pain assessment' (pharmacists, 65.4\%; physicians, 68.3\%), 'Defining goals and expectations' (61.6\%; 76.1\%), 'Development of a treatment plan' $(59.0 \% ; 66.4 \%)$ and 'Reassessment and management of longitudinal care' $(53.1 \% ; 64.3 \%)$. Finally, the scores on the 'Management of environmental issues' scale, evaluating knowledge regarding the legislation on opioid prescription, were also low $(64.4 \% ; 64.8 \%)$.

The results for individual KnowPain-50 questions are reported in Table 4. On the 'Initial pain assessment' subscale, the proportion of respondents scoring 4 or 5 (with 5 awarded for the most appropriate answer) was particularly low on questions related to the evaluation of pain. Twelve pharmacists (10.9\%) and 20 physicians (14.6\%) appropriately agreed that 'Patients may sleep in spite of severe pain' (question 28). A minority considered that, although patients can be distracted from their pain, its intensity may nonetheless be high (question 35; pharmacists, 32.7\%; physicians, 40.9\%). Overall, 36.4\% of pharmacists and $56.2 \%$ of physicians believed that changes in vital signs are not reliable indicators of pain severity (question 45). On the 'Defining goals and expectations' subscale, 18 (16.4\%) pharmacists and $60(43.8 \%)$ physicians agreed that there is good evidence that psychosocial factors predict outcomes from back surgery better than the patient's physical characteristics (question 26). When considering chronic daily pain that has persisted unchanged for years (question 32 ), $19.1 \%$ of pharmacists and $56.2 \%$ of physicians acknowledged that such pain is unlikely to have a clear cause or cure. A minority of clinicians correctly answered questions related to the use of anticonvulsants (questions 3 and 40), antidepressants (question 24), adjuvant therapy in general (question 42), and opioids (questions 41, 48 and 49). Some questions related to 'Management of environmental issues' were correctly answered by only a small proportion of pharmacists and physicians, including question 14, regarding methadone prescription for pain (pharmacists, 38.2\%; physicians, $24.8 \%$ ), and question 50 , regarding the number of doses of opioids that can be prescribed at one time (pharmacists, 54.5\%; physicians, $52.6 \%)$.

Controlling for type of clinician (physician versus pharmacist), hours of reported CEP training were positively associated with better performance on the KnowPain-50 questionnaire: $10 \mathrm{~h}$ of training raised the mean overall score by 0.3 points ( $95 \%$ CI 0.01 to 0.8 ). Sex and years of practice did not affect the overall score.

As presented in Table 5, all physicians and pharmacists acknowledged their need for additional CEP on CNCP. A majority of physicians $(65.4 \%)$ preferred interactive activities, such as problem-based learning. Pharmacists had no clear preferences; approximately equal proportions chose interactive activities $(47.7 \%)$, self-learning modules $(46.8 \%)$ and scientific presentations by peers $(41.3 \%)$. Nearly onethird of the physicians and pharmacists would appreciate a training day in a pain clinic. Most pharmacists would appreciate training about treatment-guideline recommendations $(77.1 \%)$ and the use of anticonvulsants $(64.2 \%)$, antidepressants $(61.5 \%)$, opioids $(60.6 \%)$ and anti-inflammatories $(48.6 \%)$. Training to improve specific skills and knowledge for the follow-up of CNCP patients garnered less support: detection and management of drug-related problems, 56.0\%; pharmaceutical care with analgesic dose adjustment, $54.1 \%$; non-pharmacological treatment, $53.2 \%$; and detection and management of analgesic side effects, $39.4 \%$. For physicians, the most relevant topic was the differential diagnosis of chronic pain syndromes (71.3\%). More than $40 \%$ reported that they would also like training in injection-type intervention techniques $(44.9 \%)$ and the indications and referral procedures for pain clinics (40.4\%). Approximately one-third of physicians would like training on pain assessment and on physical and psychological follow-up for CNCP patients.
Logistic regression was used to assess correlations between the subscale and overall scores on the KnowPain-50 questionnaire and the expressed need for additional training in specific areas. Physicians with a higher score on the 'Defining goals and expectations' subscale were more likely to express a need for additional training regarding 'Indications and procedures for referring patients to multidisciplinary pain-management clinic' (OR 1.04 [95\% CI 1.00 to 1.08]) and 'Psychological assessment of patient' (OR 1.05 [95\% CI 1.00 to 1.10]). Pharmacists scoring higher on the 'Initial pain assessment' subscale were more likely to express interest in additional training on 'Detection and management of drug-related problems' (OR 1.05 [95\% CI 1.00 to 1.09]). No other statistically significant correlations emerged.

\section{DISCUSSION}

A survey of primary care physicians and pharmacists actively involved in the follow-up of patients with moderate to severe CNCP revealed that CEPs on chronic pain management are relevant and perceived as necessary by all clinicians. Physicians' and pharmacists' knowledge of the general notions of chronic pain pharmacotherapy and the management of analgesic side effects was relatively good. However, deficiencies were observed in all aspects of CNCP management for specific patient populations (eg, the elderly and those at risk of addiction) and specific types of pain (eg, neuropathic pain). Based on the self-reported number of CEP sessions on chronic pain in the previous five years, $\mathrm{KAB}$ scores rose only slightly with more training. Pharmacists did not express clear preferences regarding the format of such a CEP, while physicians preferred an interactive format.

The KnowPain-50 questionnaire is one of the most thoroughly studied physician pain KAB survey tools available for general use. However, information on its psychometric properties is limited, and the questionnaire had to be adapted for community pharmacists. To our knowledge, there is no questionnaire available to measure pain $\mathrm{KAB}$ across professional groups (28-30). Based on our survey results, the internal consistency coefficients of the overall original scale (95\% CI of the Cronbach's alpha coefficients: pharmacists, 0.55 to 0.75 ; physicians, 0.71 to 0.83 ) and the overall modified scales (pharmacists, 0.53 to 0.74 ; physicians, 0.71 to 0.83 ) are similar to those presented by Harris et al (12) for physicians. The authors reported coefficients varying from 0.77 to 0.85 in various physician populations, including subscribers to continuing medical education website activities, pain experts and academics. In our study, the internal consistency of each subscale was quite low, ranging from -0.03 to 0.55 for pharmacists and from 0.03 to 0.64 for physicians. These results suggest that subscale scores should not be used to discriminate between groups of clinicians or detect changes over time (31). Indeed, Harris et al $(12,26)$ used the overall score for these purposes and never reported subscale scores.

When we asked clinicians, "In which area(s) would you like to have more training with regard to CNCP?", most of the topics of interest suggested to them were specific to either pharmacists or physicians. Ideally, we should have offered the same choices to all respondents. Despite this limitation, some interesting results emerge.

In our survey, both physicians and pharmacists exhibited deficient knowledge regarding legislative rules governing opioid prescription. Similar results have been reported in a few other surveys (32-34); in still others, the burden of regulatory oversight has not been found to be a barrier to prescribing, as opposed to concerns regarding addiction $(17-19,35)$. When asked about their needs and preferences for additional CEP sessions, no clinicians brought up the envirommental issues surrounding opioid prescription as a possible topic. This may suggest that although information on these matters is needed, clinicians may not consider it crucial.

Primary care clinicians typically encounter patients with various pain disorders. Existing guidelines are not adapted to this reality and focus on specific disorders, such as neuropathic pain (36-38), low-back pain (39) and osteoarthritis (40), as well as on opioid use (41). Several 
TABLE 4

Knowledge, attitudes and beliefs of primary care physicians and pharmacists as evaluated by individual KnowPain-50 questionnaire items

\begin{tabular}{|c|c|c|c|c|c|c|c|}
\hline & & \multicolumn{6}{|c|}{ Item score* } \\
\hline & & \multicolumn{3}{|c|}{ Pharmacists $(n=110)$} & \multicolumn{3}{|c|}{ Physicians (n=137) } \\
\hline \multicolumn{2}{|c|}{ Initial pain assessment } & 0 to 1 & 2 to 3 & 4 to 5 & 0 to 1 & 2 to 3 & 4 to 5 \\
\hline Q1 & $\begin{array}{l}\text { A 33-year-old woman complains of "all over" pain with an intensity rating ranging from } 4 \text { to } 8 \text { on the } \\
0 \text { to } 10 \text { scale, fatigue, forgetfulness, poor sleep, headaches and dizziness. This symptom com- } \\
\text { plex is most consistent with which of the following? }{ }^{\dagger \ddagger ~ C o r r e c t ~ a n s w e r: ~ F i b r o m y a l g i a ~ s y n d r o m e ~}\end{array}$ & - & - & - & $35(25.5)$ & - & $100(73.0)$ \\
\hline Q7 & $\begin{array}{l}\text { When I see consistently high scores on pain rating scales in the face of minimal or moderate } \\
\text { pathology, this means that the patient is exaggerating their pain. Correct answer: Strongly } \\
\text { disagree }\end{array}$ & $2(1.8)$ & $22(20)$ & $86(78.2)$ & $8(5.8)$ & $42(30.7)$ & $87(63.5)$ \\
\hline Q11 & $\begin{array}{l}\text { Pain complaints and degree of disability always correlate well in patients with chronic pain. } \\
\text { Correct answer: Strongly disagree }\end{array}$ & $11(10)$ & $31(28.2)$ & $67(60.9)$ & $12(8.8)$ & $28(20.4)$ & $96(70.1)$ \\
\hline Q13 & A placebo can be used to determine if pain is real. Correct answer: Strongly disagree & $24(21.8)$ & $41(37.3)$ & $44(40)$ & $10(7.3)$ & $29(21.2)$ & 98 (71.5) \\
\hline Q15 & $\begin{array}{l}\text { An MRI is a good test to identify patients with painful degenerative disc disease because } \\
\text { certain findings are consistently predictive of pain. }{ }^{\ddagger} \text { Correct answer: Strongly disagree }\end{array}$ & - & - & - & $5(3.6)$ & $20(14.6)$ & $111(81)$ \\
\hline Q17 & $\begin{array}{l}\text { I can assess patient function and activity status in my office with careful questioning of the } \\
\text { patient. } ₫ \S \text { Correct answer: Strongly agree }\end{array}$ & - & - & - & $13(9.5)$ & 44 (32.1) & $80(58.4)$ \\
\hline Q18 & $\begin{array}{l}\text { Chronic myofascial pain syndrome of the gluteal muscles can cause referred pain down the } \\
\text { leg with a similar distribution and feeling as sciatica. } ₫ \S \text { Correct answer: Strongly agree }\end{array}$ & - & - & - & $5(3.6)$ & $32(23.4)$ & $97(70.8)$ \\
\hline Q19 & $\begin{array}{l}\text { I believe that patients who complain of pain out of proportion to its cause are usually drug } \\
\text { abusers. Correct answer: Strongly disagree }\end{array}$ & $3(2.7)$ & $18(16.4)$ & $88(80)$ & $0(0)$ & $17(12.4)$ & $120(87.6)$ \\
\hline Q21 & In chronic pain, the assessment should include measurement of the pain intensit & $0(0)$ & $2(1.8)$ & $107(97.3)$ & $1(0.7)$ & $4(2.9)$ & $132(96.4)$ \\
\hline
\end{tabular}

Q28 Patients may sleep in spite of severe pain.§ Correct answer: Strongly agree

Q35 If the patient can be distracted from her/his pain, this usually means that she/he does not have high pain intensity. Correct answer: Strongly disagree

Q38 When back pain radiates down one or both legs, EMG and nerve conduction studies are

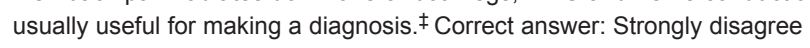

Q45 Charges in vital signs (BP, P, R, T) are reliable indicators of pain of severity. Correct answer: Strongly disagree

Defining goals and expectations

Q4 Which of the following therapies for fibromyalgia syndrome has been shown to yield the most consistent improvement ${ }^{\dagger}$ Correct answer: Aerobic exercises

Q8 There is good medical evidence that interdisciplinary treatment of back pain is effective in reducing disability, pain levels, and returning patients to work. ${ }^{\S}$ Correct answer: Strongly agree

Q9 Physical exercise will typically worsen pain and function in patients with arthritis. Correct answer: Strongly disagree

Q16 The spinal cord and higher CNS are often involved in generating the symptoms and signs of neuropathic pain, including sensitivity to touch. ${ }^{\S}$ Correct answer: Strongly agree

Q23 I have a good understanding of the general indications for surgery for acute herniated disc. $¥ \S$ Correct answer: Strongly agree

Q26 There is good evidence that psychosocial factors predict outcomes from back surgery than the patient's physical characteristics.§ Correct answer: Strongly agree

Q27 Nerve injuries are particularly likely to producing chronic neuropathic pain states. $\S$ Correct answer: Strongly agree

Q32 Chronic, daily pain that has persisted in an unchanging way for years is unlikely to have a clear cause or cure. ${ }^{\S}$ Correct answer: Strongly agree

Q33 Early return to activities is one of my primary goals when treating a patient with recent onset back pain.§ Correct answer: Strongly agree

Q36 In the majority of cases, we have the technology to determine the precise pathologic cause of chronic pain. Correct answer: Strongly disagree

Development of a treatment plan

Q2 Which of the (one) following statements is true regarding selective COX-2 inhibitors? ${ }^{\dagger}$ Correct answer: They are no more effective as an analgesic than nonselective NSAIDs.

Q3 Anticonvulsivants and analgesic antidepressants obtain about a 50\% response rate (pain intensity reduction in half of patients treated) in treating neuropathic pain. Which of the following drug classes obtains similar results ${ }^{\dagger}$ Correct answer: Opioids

Q12 Antidepressants usually do not improve symptoms and function in chronic pain patients. Correct answer: Strongly disagree

Q22 Elderly patients cannot tolerate medications such as opioids for pain. Correct answer: Strongly disagree

Q24 SSRIs are effective treatment for neuropathic pain. Correct answer: Strongly disagree

$57(51.8) 40(36.4) \quad 12(10.9) 77(56.2) \quad 40(29.2) 20(14.6)$

$17(15.5) 57(51.8) \quad 36(32.7) \quad 14(10.2) \quad 65(47.4) 56(40.9)$

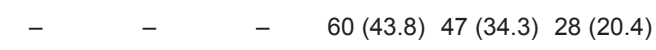

$15(13.6) 54(49.1) \quad 40(36.4) \quad 9(6.6) \quad 50(36.5) \quad 77(56.2)$

$76(69.1) \quad-\quad 34(30.9) 20(14.6) \quad-\quad 116(84.7)$

$7(6.4) \quad 24(21.8) \quad 79(71.8) \quad 4(2.9) \quad 7(5.1) \quad 126(92)$

$2(1.8) \quad 13(11.8) \quad 95(86.4) \quad 3(2.2) \quad 15(10.9) 119(86.9)$

$13(11.8) 23(20.9) 72(65.5) 18(13.1) 24(17.5) 92(67.2)$

$-\quad \quad-\quad \quad-\quad 2(1.5) \quad 33(24.1) 101(73.7)$

$29(26.4) \quad 61(55.5) \quad 18(16.4) \quad 8(5.8) \quad 67(48.9) \quad 60(43.8)$

$4(3.6) \quad 13(11.8) \quad 92(83.6) \quad 1(0.7) \quad 26(19) \quad 109(79.6)$

$66(60) \quad 23(20.9) \quad 21(19.1) 22(16.1) \quad 37(27) \quad 77(56.2)$

$11(10) \quad 37(33.6) \quad 61(55.5) \quad 1(0.7) \quad 19(13.9) 116(84.7)$

$8(7.3) \quad 41(37.3) \quad 61(55.5) \quad 8(5.8) \quad 32(23.4) \quad 96(70.1)$

$39(35.5) \quad-\quad 71(64.5) 26(19) \quad-\quad 109(79.6)$

$64(58.2) \quad-\quad 43(39.1) 65(47.4) \quad-\quad 68(49.6)$

$4(3.6) \quad 15(13.6) 90(81.8) \quad 1(0.7) \quad 15(10.9) 121(88.3)$

$5(4.5) \quad 21(19.1) \quad 82(74.5) \quad 5(3.6) \quad 14(10.2) 118(86.1)$

$44(40) \quad 42(38.2) \quad 22(20) \quad 50(36.5) \quad 58(42.3) \quad 29(21.2)$

Continued on next page 
TABLE 4 - CONTINUED

Knowledge, attitudes and beliefs of primary care physicians and pharmacists as evaluated by individual KnowPain-50 questionnaire items

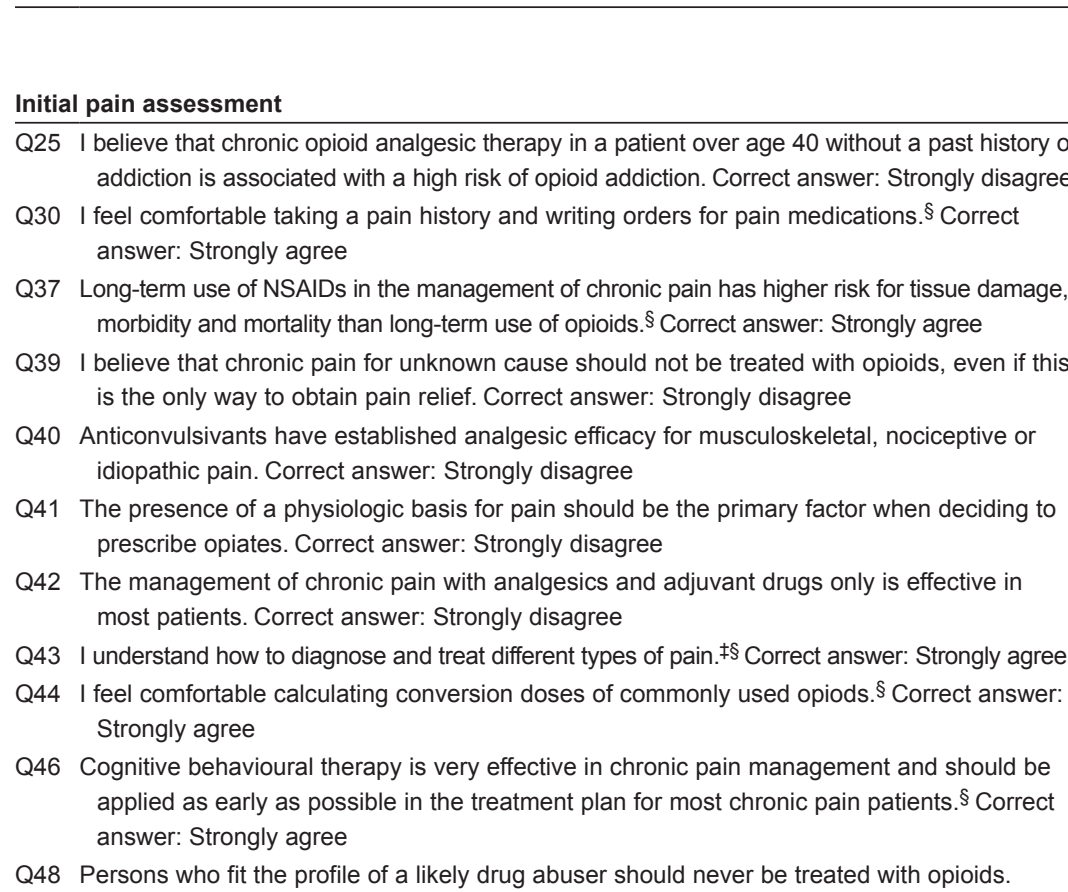
Correct answer: Strongly disagree

\section{Implementation of a treatment plan}

Q5 The most common adverse side effect of opioid therapy is:... ${ }^{\dagger}$ Correct answer: Constipation

Q34 Morphine-induced sedation is only a transient problem and will usually clear with continued

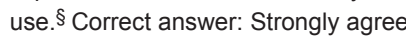

Q47 There is a limit or 'ceiling' to the dosage of pure agonist opioids (eg, morphine) that can be used to control a patient's pain. Correct answer: Strongly disagree

Reassessment and management of longitudinal care

Q49 I believe that analgesic tolerance to opioids usually limits long-term use. Correct answer: Strongly disagree

Management of environmental issues

Q6 If my opioid prescribing was investigated tomorrow, I am confident that I would pass.§ Correct answer: Strongly agree

Q10 Under federal regulations, it is not lawful to prescribe an opioid to treat pain in a patient with a diagnosed substance use disorder. Correct answer: Strongly disagree

Q14 It is illegal for a physician to prescribe methadone for pain, unless he/she is certified in addiction medicine. Correct answer: Strongly disagree

Q20 Under federal regulations, it is permitted to issue prescriptions that are postdated. Correct answer: Strongly disagree

Q29 I know how to obtain information about both state and federal requirements for prescribing opioids.§ Correct answer: Strongly agree

Q31 I am confident that I understand state and federal requirements for prescribing opioids analgesics for chronic pain.§ Correct answer: Strongly agree

Q50 Under federal regulations, there are limits on the number of dosages of opioids that can be prescribed at one time. Correct answer: Strongly disagree

\section{Pharmacotherapy}

P1 Amongst the following choices, which best represents the classes of first line medication recommended for the treatment of patients suffering from chronic neuropathic pain? ${ }^{\dagger}$ Correct answer: The anticonvulsivants and the antidepressants.

P2 What is the recommended therapy for the treatment of constipation in patients receiving chronic opioid therapy $?^{\dagger}$ Correct answer: The combination of a stool softener and a stimulant laxative is ideal.

P3 Which of the following affirmations is true ? $^{\dagger}$ Correct answer: Among patients on nonselective NSAIDs, only those at risk of gastric toxicity should receive gastroprotective agent.

P4 Amongst the following choices, in which cases would you prefer acetaminophen to an NSAID to control pain? ${ }^{\dagger}$ Correct answer: Suffer from or have risk factor for chronic kidney disease and/or gastric pathology.
Item score*

\begin{tabular}{ccccccc}
\hline \multicolumn{3}{c}{ Pharmacists $(\mathrm{n}=\mathbf{1 1 0})$} & & \multicolumn{3}{c}{ Physicians $(\mathrm{n}=137)$} \\
\hline $\mathbf{0}$ to $\mathbf{1}$ & $\mathbf{2}$ to $\mathbf{3}$ & $\mathbf{4}$ to $\mathbf{5}$ & & $\mathbf{0}$ to $\mathbf{1}$ & $\mathbf{2}$ to $\mathbf{3}$ & $\mathbf{4}$ to $\mathbf{5}$ \\
\hline $15(13.6)$ & $34(30.9)$ & $59(53.6)$ & & $9(6.6)$ & $29(21.2)$ & $99(72.3)$
\end{tabular}

$26(23.6) 56(50.9) \quad 27(24.5) \quad 3(2.2) \quad 29(21.2) 104(75.9)$

$19(17.3) 48(43.6) 43(39.1) \quad 10(7.3) \quad 46(33.6) \quad 80(58.4)$

$13(11.8) \quad 28(25.5) \quad 69(62.7) \quad 8(5.8) \quad 41(29.9) \quad 87(63.5)$

$41(37.3) \quad 43(39.1) 25(22.7) 53(38.7) \quad 44(32.1) \quad 39(28.5)$

$29(26.4) \quad 54(49.1) \quad 24(21.8) \quad 37(27) \quad 55(40.1) \quad 44(32.1)$

$43(39.1) \quad 52(47.3) \quad 15(13.6) \quad 37(27) \quad 63(46) \quad 37(27)$

$\begin{array}{llllll}- & - & - & 2(1.5) & 51(37.2) & 84(61.3)\end{array}$

$6(5.5) \quad 39(35.5) \quad 65(59.1) \quad 5(3.6) \quad 34(24.8) \quad 98(71.5)$

$3(2.7) \quad 29(26.4) \quad 78(70.9) \quad 4(2.9) \quad 38(27.7) \quad 94(68.6)$

$15(13.6) \quad 56(50.9) \quad 39(35.5) \quad 13(9.5) \quad 64(46.7) \quad 60(43.8)$

$22(20) \quad-\quad 87(79.1) \quad 4(2.9) \quad-\quad 132(96.4)$

$8(7.3) \quad 28(25.5) \quad 74(67.3) \quad 14(10.2) \quad 44(32.1) \quad 78(56.9)$

$22(20) \quad 16(14.5) \quad 72(65.5) \quad 15(10.9) \quad 30(21.9) \quad 92(67.2)$

$27(24.5) \quad 44(40) \quad 39(35.5) \quad 18(13.1) \quad 49(35.8) \quad 69(50.4)$

$7(6.4) \quad 38(34.5) \quad 64(58.2) \quad 3(2.2) \quad 29(21.2) 105(76.6)$

$12(10.9) 23(20.9) 75(68.2) \quad 10(7.3) \quad 24(17.5) 103(75.2)$ $58(52.7) \quad 9(8.2) \quad 42(38.2) \quad 94(68.6) \quad 8(5.8) \quad 34(24.8)$

$44(40) \quad 13(11.8) \quad 52(47.3) \quad 13(9.5) \quad 24(17.5) \quad 100(73)$

$7(6.4) \quad 24(21.8) \quad 79(71.8) \quad 31(22.6) \quad 46(33.6) \quad 59(43.1)$

$4(3.6) \quad 29(26.4) \quad 77(70) \quad 8(5.8) \quad 38(27.7) \quad 90(65.7)$

$21(19.1) 29(26.4) 60(54.5) 24(17.5) 41(29.9) 72(52.6)$

$51(46.4) \quad-\quad 57(51.8) 34(24.8)-$

$103(75.2)$

$8(7.3) \quad-\quad 102(92.7) 35(25.5) \quad-\quad 102(74.5)$

$59(53.6) \quad-\quad 51(46.4) 72(52.6) \quad-\quad 64(46.7)$

$24(21.8) \quad-\quad 86(78.2) 46(33.6) \quad-\quad 90(65.7)$ 
TABLE 4 - CONTINUED

Knowledge, attitudes and beliefs of primary care physicians and pharmacists as evaluated by individual KnowPain-50 questionnaire items

\begin{tabular}{|c|c|c|c|c|c|c|c|}
\hline & & \multicolumn{6}{|c|}{ Item score* } \\
\hline & & \multicolumn{3}{|c|}{ Pharmacists $(n=110)$} & \multicolumn{3}{|c|}{ Physicians (n=137) } \\
\hline \multicolumn{2}{|c|}{ Initial pain assessment } & 0 to 1 & 2 to 3 & 4 to 5 & 0 to 1 & 2 to 3 & 4 to 5 \\
\hline P5 & $\begin{array}{l}\text { Which of the following doses of hydromorphone per os is considered equivalent to } 10 \mathrm{mg} \text { of } \\
\text { morphine? }{ }^{\dagger} \text { Correct answer: } 2 \mathrm{mg}\end{array}$ & $24(21.8)$ & - & $84(76.4)$ & $32(23.4)$ & - & $104(75.9)$ \\
\hline P6 & $\begin{array}{l}\text { Concerning fibromyalgia, which of the following affirmations is true }{ }^{\dagger} \text { Correct answer: } \\
\text { Clinical studies have demonstrated the effectiveness and safety of pregabalin. }\end{array}$ & $32(29.1)$ & - & $74(67.3)$ & $29(21.2)$ & - & $105(76.6)$ \\
\hline P7 & $\begin{array}{l}\text { Concerning the following tricyclic antidepressants, which should be avoided when treating } \\
\text { senior patients, given the adverse side effects of anticholinergics and sedatives? }{ }^{\dagger} \text { Correct } \\
\text { answer: Amitriptyline }\end{array}$ & $17(15.5)$ & - & $90(81.8)$ & $29(21.2)$ & - & $102(74.5)$ \\
\hline
\end{tabular}

TABLE 5

Needs and preferences of physicians and pharmacists regarding the format and content of a continuing education program (CEP) for chronic noncancer pain (CNCP) and its treatment

\begin{tabular}{|c|c|c|}
\hline & Pharmacists $(n=109)$ & Physicians ( $n=136)$ \\
\hline \multicolumn{3}{|c|}{ From your standpoint, is there a need for a CEP in CNCP for primary care physicians (or pharmacists)? } \\
\hline \multicolumn{3}{|l|}{ What would be the best educational vehicle(s) or method(s) for a CEP? } \\
\hline Self-learning modules (paper format) & $51(46.8)$ & $48(35.5)$ \\
\hline Scientific presentations by peers & $45(41.3)$ & $55(40.4)$ \\
\hline Self-learning modules (Internet based) & 37 (33.9) & $58(42.6)$ \\
\hline Training days in a pain management clinic & $31(28.4)$ & $37(27.2)$ \\
\hline Other & $0(0.0)$ & $10(7.4)$ \\
\hline \multicolumn{3}{|l|}{ In which area(s) would you like to have more training with regard to CNCP? } \\
\hline Review of Canadian and/or Quebec guideline recommendations & $84(77.1)$ & $64(47.1)$ \\
\hline \multicolumn{3}{|l|}{ Indication and use of: } \\
\hline Anticonvulsants & $70(64.2)$ & $41(30.1)$ \\
\hline \multicolumn{3}{|l|}{ Pharmacists' specific topics } \\
\hline Detection and management of drug-related problems & $61(56.0)$ & - \\
\hline Pharmaceutical care with analgesic dose adjustment & $59(54.1)$ & - \\
\hline Nonpharmacological methods to manage chronic pain & $58(53.2)$ & - \\
\hline Detection and management of side effects & $43(39.4)$ & - \\
\hline Physician-pharmacist workshop on collaborative practices & $41(37.6)$ & - \\
\hline Diagnosis update & $30(27.5)$ & - \\
\hline \multicolumn{3}{|l|}{ Physicians' specific topics } \\
\hline Differential diagnoses of chronic pain syndromes & & $97(71.3)$ \\
\hline Trigger-point-injection intervention techniques; joint or muscle infiltration & & $61(44.9)$ \\
\hline Psychological techniques for chronic pain & & $55(40.4)$ \\
\hline
\end{tabular}

Data presented as $n$ (\%). Coxib Selective cyclooxygenase-2 inhibitor; NSAID Nonsteroidal anti-inflammatory drug; PBL Problem-based learning

studies suggest that primary care physicians and pharmacists are not aware of - or do not follow - guideline recommendations $(13,14,42,43)$. In our survey, $77.1 \%$ of pharmacists and $47.1 \%$ of physicians identified the review of guideline recommendations as an area of interest for additional training. The performance of clinicians on the different KnowPain-50 questions shows that they also need to learn better how to apply these recommendations in specific clinical situations. Such deficient pain KAB has also been reported by others $(11,15)$. 
Surprisingly, we found no significant correlation between the perceived needs of clinicians regarding CEPs and their level of pain KAB. This result highlights the importance of basing the development of CEPs on objective questionnaires such as the KnowPain-50.

In our survey, more CEP training was positively associated with higher levels of pain KAB. However, the correlation was low; $10 \mathrm{~h}$ of training in the past five years were associated with an increase of 0.3 points in the overall KnowPain-50 score. It is important to note that previous attendance at CEP sessions was based on self-reported cross-sectional data and may have been overestimated by social desirability (tendency to give socially desirable answers) and memory biases. Furthermore, the recall period was very long (five years). These factors may explain why our results are not in line with those reported by others. For example, Harris et al (26) found that the KnowPain-50 questionnaire could detect an improvement in $\mathrm{KAB}$ three months after attending a speaker's presentation and a publicly available online continuing medical education program. Other investigators have also shown that CEPs are able to improve knowledge (44-46), clinical practices and patient outcomes (47).

In our survey, $65.4 \%$ of physicians and $47.7 \%$ of pharmacists selected interactive training as one of their preferred educational vehicles. This is an interesting finding, considering that a CEP based on a mix of interactive and didactic methods has been shown to be among the most effective approaches for improving professional practice (47). Also noteworthy is the fact that despite the rapid growth in online CEPs (48), only $42.6 \%$ of physicians and $33.9 \%$ of pharmacists indicated an interest in Internet-based self-learning modules. Internet-based technologies are evolving rapidly and may now include multifaceted interventions such as interactive cases, enabling tools, and didactic presentations. Asynchronous discussions with peers and a facilitator may also be added to allow participants to discuss the content of the program and ask questions $(49,50)$. This appears to improve physician satisfaction (51). Primary care clinicians may not be fully aware of the potential benefits of Internet-based training. We have no information about the participants' previous exposure to different formats of CEPs.

In primary care, pharmacists can play an important role in the management of $\mathrm{CNCP}(10)$. In several studies, pharmacist interventions were associated with positive patient outcomes (52-55). However, lack of time and remuneration $(56,57)$ may limit their involvement. Some may see treating patients with chronic pain as extremely time consuming $(14,43)$. This concern has been documented among primary care physicians as well (13). In our study, it is encouraging to note that more than one-half of the pharmacists were interested in a CEP on the provision of advanced pharmaceutical care, such as detection and management of drug-related problems, pharmaceutical care with analgesic dose adjustment and nonpharmacological methods of pain management. However, only $37.6 \%$ reported an interest in participating in a physician-pharmacist workshop on collaborative practices; our data provide no explanation for this low response. Given the pharmacists' level of knowledge about pain and its treatment, they may not feel prepared to initiate active collaborative practices. Similar information from physicians is not available.

\section{Strengths and limitations}

The present study provides a unique overview of the $\mathrm{KAB}$ of primary care physicians and pharmacists currently involved in managing CNCP patients. A modified version of the KnowPain-50 questionnaire was carefully developed for pharmacists by a panel of experts and demonstrated similar reliability. The implementation of a multistep approach to sending out the survey resulted in a relatively high participation rate (5). Participating clinicians may not be representative of the entire community of primary care physicians and pharmacists. However, our sample probably consisted of clinicians actually managing chronic pain patients on a day-to-day basis and may, therefore, represent a 'best case' scenario.

Despite the rigorous approach taken by the developers of the KnowPain-50 questionnaire, it nonetheless includes 'double-barrelled' questions (ask two or more questions at the same time, each of which can be answered differently) that may be difficult to answer (eg, question 32, regarding the cause and cure of pain, and question 30, regarding taking pain history and writing orders). This may reduce the interpretability of the results as well as the reliability of the questionnaire. The questionnaire may also be perceived as unbalanced, given that, except for question 5 , all the questions on opioids tend to cast them in a positive light (eg, questions $22,25,34,37,39$ and 48). Furthermore, the finding regarding the impact of additional CEP training on chronic pain $\mathrm{KAB}$ may be inaccurate because precise self-reporting of the number of hours of such activities in the past five years is rather difficult. Unfortunately, we did not ask pharmacists or physicians for consent to link the results of this survey to the information on their patients in the cohort. Consequently, it was not possible to investigate whether more appropriate $\mathrm{KAB}$ was associated with better management of CNCP and greater patient satisfaction.

\section{CONCLUSION}

The present study clearly indicates that, although most pharmacists and physicians had participated in CEPs about chronic pain management, their KAB remain far from optimal. CEP sessions need to target their knowledge and clinical competencies as well as their inappropriate beliefs and attitudes about pain and its treatment.

DISCLOSURES: The authors have no conflicts of interest to declare.

ACKNOWLEDGEMENTS: The authors thank all the physicians and pharmacists involved in this study, and Chantal Legris for her assistance in the preparation of this article. Lyne Lalonde and Sylvie Perreault are research scholars of the Fonds de recherche du Québec - Santé.

FINANCIAL SUPPORT: This study was supported by the Canadian Institutes of Health Research (CIHR) (grant number CAH-86787) in partnership with AstraZeneca Canada Inc. Part of the study was also funded by Pfizer Canada Inc.

\section{REFERENCES}

1. Furlan AD, Reardon R, Weppler C, National Opioid Use Guideline Group. Opioids for chronic noncancer pain: A new Canadian practice guideline. CMAJ 2010;182:923-30.

2. Moulin DE, Clark AJ, Speechley M, Morley-Forster PK. Chronic pain in Canada - prevalence, treatment, impact and the role of opioid analgesia. Pain Res Manag 2002;7:179-84

3. Gouvernement du Québec. Portrait de santé du Québec et de ses régions 2006 : les analyses - Deuxième rapport national sur l'état de santé de la population du Québec. Québec: Publications du Québec; 2006.

4. Millar WJ. Chronic pain. Health Rep 1996;7:47-53, 1-8.

5. Breivik H, Collett B, Ventafridda V, Cohen R, Gallacher D. Survey of chronic pain in Europe: Prevalence, impact on daily life, and treatment. Eur J Pain 2006;10:287-333.

6. Gureje O, Von Korff M, Simon GE, Gater R. Persistent pain and well-being: A World Health Organization Study in Primary Care. JAMA 1998;280:147-51.

7. Boulanger A, Clark AJ, Squire P, Cui E, Horbay GL. Chronic pain in Canada: Have we improved our management of chronic noncancer pain? Pain Res Manag 2007;12:39-47.

8. Turk DC. Chronic non-malignant pain patients and health economic consequences. Eur J Pain 2002;6:353-5.

9. Blyth FM, March LM, Nicholas MK, Cousins MJ. Chronic pain, work performance and litigation. Pain 2003;103:41-7.

10. Silcock J, Moffett JK, Edmondson H, Waddell G, Burton AK. Do community pharmacists have the attitudes and knowledge to support evidence based self-management of low back pain? BMC Musculoskelet Disord 2007;8:10.

11. Dahan R, Reis S, Borkan J, et al. Is knowledge a barrier to implementing low back pain guidelines? Assessing the knowledge of Israeli family doctors. J Eval Clin Pract 2008;14:785-91.

12. Harris JM Jr, Fulginiti JV, Gordon PR, et al. KnowPain-50: A tool for assessing physician pain management education. Pain Med 2008;9:542-54.

13. Ponte CD, Johnson-Tribino J. Attitudes and knowledge about pain: An assessment of West Virginia family physicians. Fam Med 2005;37:477-80. 
14. Ponte CD, Johnson-Tribino J. Attitudes and knowledge about pain among West Virginia pharmacists. J Am Pharm Assoc 2007;47:379-82.

15. Stannard C, Johnson M. Chronic pain management - can we do better? An interview-based survey in primary care. Curr Med Res Opin 2003;19:703-6.

16. American Pain Society. Chronic pain in America: Roadblocks to relief. <www.doctordeluca.com/Library/Pain/

ChronicPainRoadblocks.htm> (Accessed September 24, 2013).

17. Morley-Forster PK, Clark AJ, Speechley M, Moulin DE. Attitudes toward opioid use for chronic pain: A Canadian physician survey. Pain Res Manag 2003;8:189-94.

18. Weinstein SM, Laux LF, Thornby JI, et al. Physicians' attitudes toward pain and the use of opioid analgesics: Results of a survey from the Texas Cancer Pain Initiative. South Med J 2000;93:479-87.

19. Wenghofer EF, Wilson L, Kahan M, et al. Survey of Ontario primary care physicians' experiences with opioid prescribing. Can Fam Physician 57:324-32.

20. Potter M, Schafer S, Gonzalez-Mendez E, et al. Opioids for chronic nonmalignant pain. Attitudes and practices of primary care physicians in the UCSF/Stanford Collaborative Research Network. University of California, San Francisco. J Fam Pract 2001;50:145-51.

21. Le programme ACCORD. Formation et intervention en soins de première ligne. <www.programmeaccord.org/volets/premiereligne> (Accessed April 22, 2013).

22. Jouini G, Choinière M, Martin E, et al. Pharmacotherapeutic management of noncancer chronic pain in primary care: Lessons for pharmacists. J Pain Res 2014;7:163-73.

23. Jouini G. Pharmacothérapie de la douleur chronique noncancéreuse chez des patients suivi en première ligne (electronic dissertation). <https://papyrus.bib.umontreal.ca/xmlui/ handle/1866/8342> (Accessed August 8, 2013).

24. Gouvernement du Québec. Atlas de la santé et des services sociaux du Québec. 2009.

25. Dillman DA. Mail and Internet Surveys: The Tailored Design Method. New York: John Wiley \& Sons Inc, 2000.

26. Harris JM Jr, Elliott TE, Davis BE, Chabal C, Fulginiti JV, Fine PG. Educating generalist physicians about chronic pain: Live experts and online education can provide durable benefits. Pain Med 2008;9:555-63.

27. Streiner D, Norman G. Health Measurement Scales: A Practical Guide to Their Development and Use. Toronto: Oxford University Press, 1989.

28. Rose L, Smith O, Gelinas C, et al. Critical care nurses' pain assessment and management practices: A survey in Canada. Am J Crit Care 21:251-9.

29. Weinstein SM, Laux LF, Thornby JI, et al. Medical students' attitudes toward pain and the use of opioid analgesics: Implications for changing medical school curriculum. South Med J 2000;93:472-8.

30. Blumenthal D, Gokhale M, Campbell EG, Weissman JS. Preparedness for clinical practice: Reports of graduating residents at academic health centers. JAMA 2001;286:1027-34.

31. Bowling A. Measuring Disease: A Review of Disease Specific Quality of Life Measurement Scales. Michigan: Open Press, 2001.

32. Gilson AM. State medical board members' attitudes about the legality of chronic prescribing to patients with noncancer pain: The influence of knowledge and beliefs about pain management, addiction, and opioid prescribing. J Pain Symptom Manage 2010;40:599-612.

33. Greenwald BD, Narcessian EJ. Opioids for managing patients with chronic pain: Community pharmacists' perspectives and concerns. J Pain Symptom Manage 1999;17:369-75.

34. Wolfert MZ, Gilson AM, Dahl JL, Cleary JF. Opioid analgesics for pain control: Wisconsin physicians' knowledge, beliefs, attitudes, and prescribing practices. Pain Med 2010;11:425-34.

35. Turk DC, Brody MC, Okifuji EA. Physicians' attitudes and practices regarding the long-term prescribing of opioids for non-cancer pain. Pain 1994;59:201-8.

36. Boulanger A, Arsenault P, Béland A, et al. Algorithme et traitement de la douleur neuropathique. Recommandations d'un forum québécois sur la douleur neuropathique. MedActuel DPC 2008;8:25-30.
37. Moulin DE, Clark AJ, Gilron I, et al. Pharmacological management of chronic neuropathic pain - consensus statement and guidelines from the Canadian Pain Society. Pain Res Manag 2007;12:13-21.

38. O'Connor AB, Dworkin RH. Treatment of neuropathic pain: An overview of recent guidelines. Am J Med 2009;122(10 Suppl):S22-32.

39. Chou R, Qaseem A, Snow V, et al. Diagnosis and treatment of low back pain: A joint clinical practice guideline from the American College of Physicians and the American Pain Society. Ann Intern Med 2007;147:478-91.

40. Zhang W, Moskowitz RW, Nuki G, et al. OARSI recommendations for the management of hip and knee osteoarthritis, Part II: OARSI evidence-based, expert consensus guidelines. Osteoarthritis Cartilage 2008;16:137-62

41. National Pain Centre, McMaster University. Canadian guideline for safe and effective use of opioids for chronic non-cancer pain. $<$ http://nationalpaincentre.mcmaster.ca/opioid/> (Accessed October 4, 2013)

42. Glauser TA, Salinas GD, Roepke NL, et al. Management of mildto-moderate osteoarthritis: A study of the primary care perspective. Postgrad Med 2011;123:126-34.

43. Wallace JM. The pharmacist's role in managing chronic opioid therapy. Curr Pain Headache Rep 2006;10:245-52.

44. Sullivan MD, Gaster B, Russo J, et al. Randomized trial of webbased training about opioid therapy for chronic pain. Clin J Pain 2010;26:512-7.

45. Kowacs PA, Twardowschy CA, Piovesan EJ, et al. General practice physician knowledge about headache: Evaluation of the municipal continual medical education program. Arq Neuropsiquiatr 2009;67:595-9.

46. Sargeant JM, Purdy RA, Allen MJ, Nadkarni S, Watton L, O'Brien P. Evaluation of a CME problem-based learning Internet discussion. Acad Med 2000;75(10 Suppl):S50-2.

47. Forsetlund L, Bjorndal A, Rashidian A, et al. Continuing education meetings and workshops: Effects on professional practice and health care outcomes. Cochrane Database Syst Rev 2009;(2):CD003030.

48. Harris JM Jr, Sklar BM, Amend RW, Novalis-Marine C. The growth, characteristics, and future of online CME. J Contin Educ Health Prof 2010;30:3-10.

49. Legris ME, Charbonneau-Séguin N, Desforges K, et al. Pharmacist Web-based training program on medication use in chronic kidney disease patients: Impact on knowledge, skills, and satisfaction. J Contin Educ Health Prof 2011;31:140-50.

50. Young KJ, Kim JJ, Yeung G, Sit C, Tobe SW. Physician preferences for accredited online continuing medical education. J Contin Educ Health Prof 2011;31:241-6.

51. Curran VR, Fleet LJ, Kirby F. A comparative evaluation of the effect of Internet-based CME delivery format on satisfaction, knowledge and confidence. BMC Med Educ 2010;10:10.

52. Machado M, Bajcar J, Guzzo GC, Einarson TR. Sensitivity of patient outcomes to pharmacist interventions. Part II: Systematic review and meta-analysis in hypertension management. Ann Pharmacother 2007;41:1770-81.

53. Machado M, Bajcar J, Guzzo GC, Einarson TR. Sensitivity of patient outcomes to pharmacist interventions. Part I: Systematic review and meta-analysis in diabetes management. Ann Pharmacother 2007;41:1569-82.

54. Machado M, Nassor N, Bajcar JM, Guzzo GC, Einarson TR. Sensitivity of patient outcomes to pharmacist interventions. Part III: Systematic review and meta-analysis in hyperlipidemia management. Ann Pharmacother 2008;42:1195-207.

55. Chisholm-Burns MA, Kim Lee J, Spivey CA, et al. US pharmacists' effect as team members on patient care: Systematic review and meta-analyses. Med Care 2010;48:923-33.

56. Eades CE, Ferguson JS, O'Carroll RE. Public health in community pharmacy: A systematic review of pharmacist and consumer views. BMC Public Health 2011;11:582.

57. Wang J, Hong SH, Meng S, Brown LM. Pharmacists' acceptable levels of compensation for MTM services: A conjoint analysis. Res Social Adm Pharm 2011;7:383-95. 


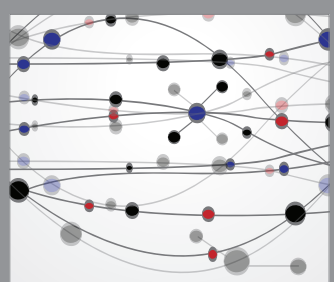

The Scientific World Journal
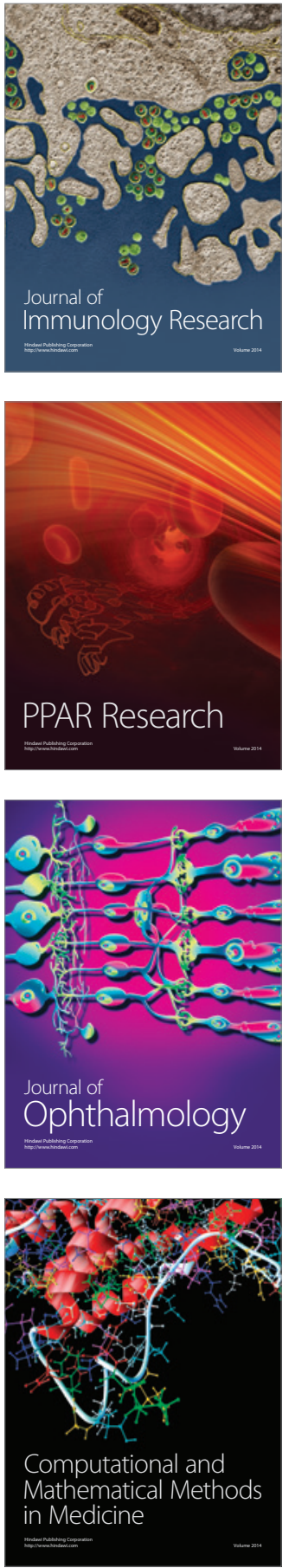

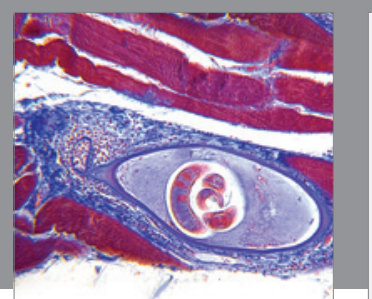

Gastroenterology Research and Practice

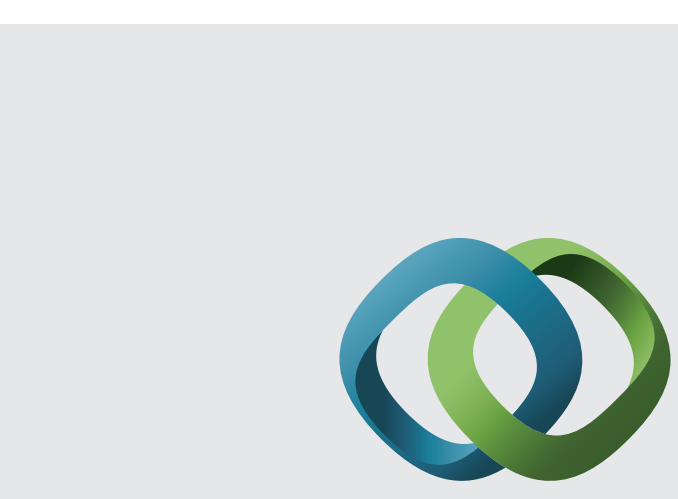

\section{Hindawi}

Submit your manuscripts at

http://www.hindawi.com
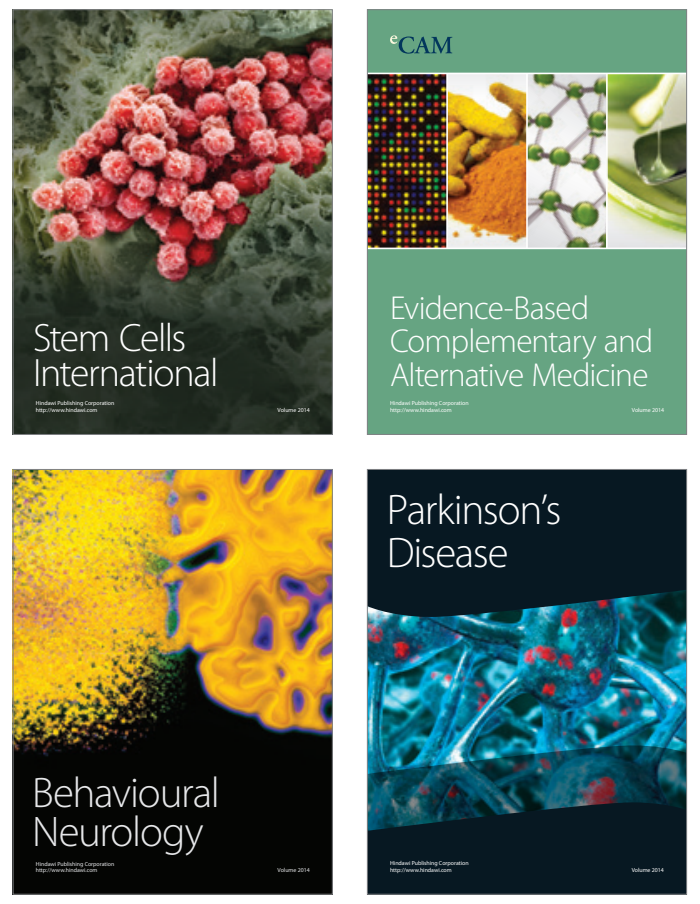
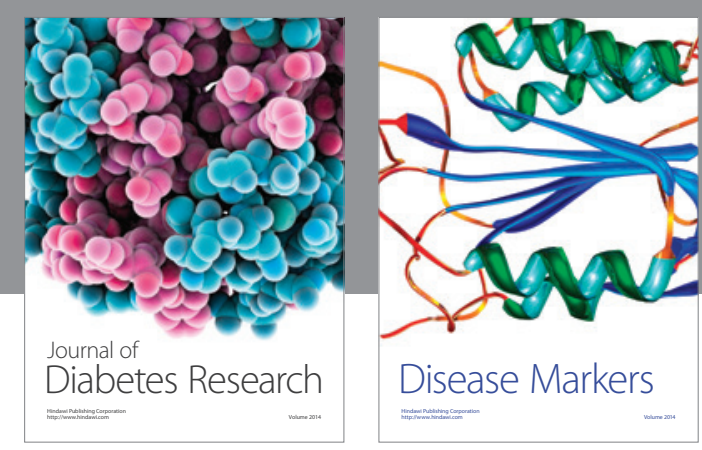

Disease Markers
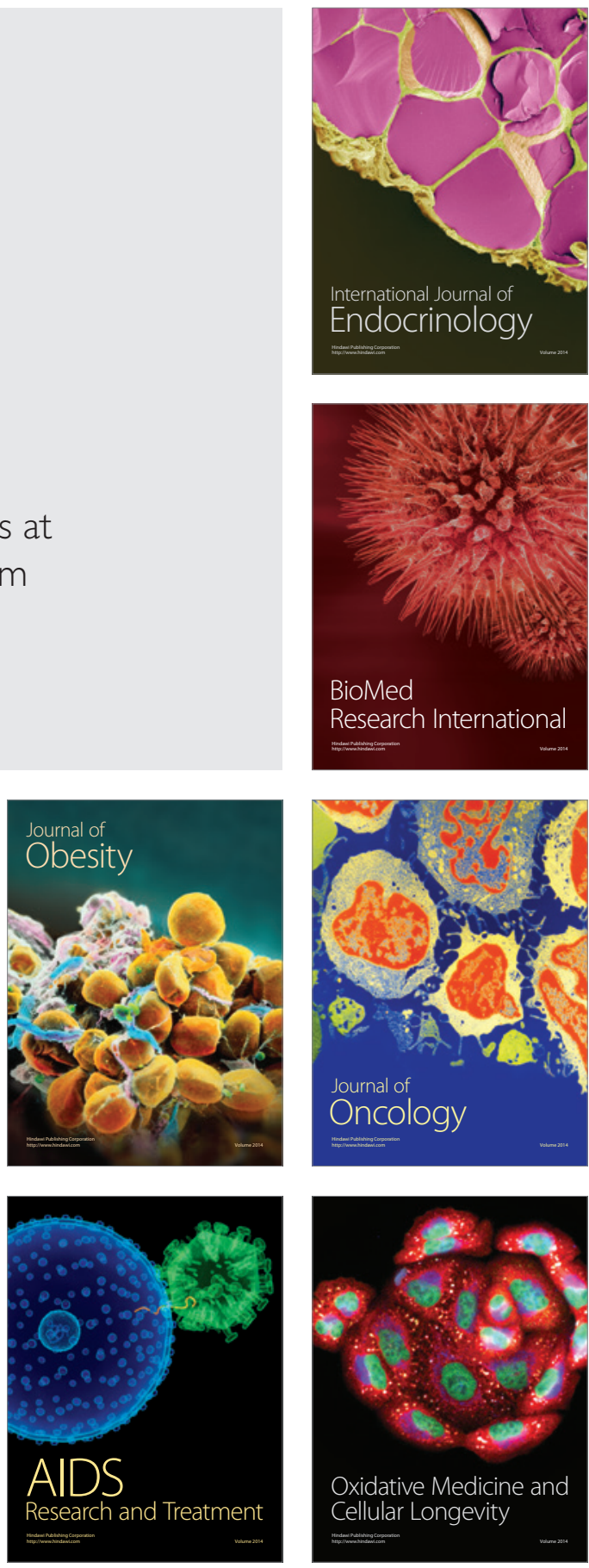